\title{
The Effectiveness of Carpal Bone Mobilization Accompanied by Night Splinting in Idiopathic Carpal Tunnel Syndrome
}

\author{
Berna GÜNAY, Alev ALP \\ Department of Physical Medicine and Rehabilitation, Uludağ University Faculty of Medicine, Bursa, Turkey
}

\begin{abstract}
Objective: The aim of this study was to investigate the effectiveness of carpal bone mobilization (CBM) and night splinting and to compare it with night splinting as a control group in the treatment of Carpal Tunnel Syndrome (CTS).

Methods: In the single-blind (assessor) prospective randomised controlled trial, a total of 40 patients with mild to moderate CTS were diagnosed by electroneuromyography (ENMG). In Group $1(n=20)$, patients received CBM three times a week, total of 10 times, and used neutral volar wrist splint at night for 3 weeks. Patients in Group $2(n=20)$ used only neutral volar wrist splint at night for 3 weeks. All of the patients were assessed at baseline and at the $3^{\text {rd }}$ month with respect to pain intensity using a numerical rating scale (0-10), handgrip and pinchgrip strength, functional status and symptom severity using the Boston Carpal Tunnel Questionnarie (BCTQ), and ENMG measurements.

Results: There were improvements in all of the clinical variables, distal sensory latancy, and sensory nerve action potentials of the median nerve in Group 1. In Group 2, there was improvement in only BCTQ symptom severity and night/day pain intensity at the $3^{\text {rd }}$ month. Improvement in pinchgrip strength and BCTQ functional status were superior in Group 1 when compared to Group 2 at the $3^{\text {rd }}$ month.

Conclusion: Both of the treatment modalities may be recommended for symptomatic relief. However, CBM combined with splinting may be a better choice for functional and strength amelioration as a non-invasive alternative treatment modality in CTS.

Keywords: Boston carpal tunnel questionnarie, carpal bone mobilization, carpal tunnel syndrome, electoneuromyography, pain
\end{abstract}

\section{Introduction}

Carpal tunnel is an anatomical compartment in the wrist, which includes the median nerve and flexor tendons inside, surrounded by the carpal bones scaphoid, trapezium, and hamatum that form an arch. Thus, carpal tunnel syndrome (CTS) is the entrapment neuropathy of the median nerve that causes paresthesia, pain, numbness, and weakness of the flexor pollicis brevis, opponens pollicis, and abductor pollicis brevis in the innervation area of the median nerve because of its compression in the wrist (1). Most of the patients experience pain at night and have abnormal sensations. Shaking of the suffering hand relieves the symptoms. Electrodiagnostic evaluation (electromyography and nerve conduction velocity) can objectively reveal the median nerve dysfunction $(2,3)$. Prolonged terminal latancy of sensory/motor nerve is found in most CTS hands, which is influenced by demyelination that results in conduction block and slowing at the carpal tunnel (4). If electrodiagnostic evaluation is normal, CTS may be considered either absent or mild.

Many options are available for the treatment of patients with CTS, and the modality chosen depends on the severity of nerve dysfunction (mild, moderate, or severe). The specific choice of 
therapy will also vary according to patient preference and availability. For patients with mild to moderate CTS, conservative therapy is generally considered to be a reasonable first option with successful outcomes ranging from $20 \%$ to $93 \%$ (5-7). One review showed good results for splinting, ultrasound, nerve gliding exercises, carpal bone mobilization, magnetic therapy, and yoga for people with carpal tunnel syndrome (8). Combined therapy may be more effective than the use of any single modality (8-10). However, a recent guideline produced by the American Academy of Orthopedic Surgeons assigned lower grades of evidence to most of these treatments (11).

Many health professionals suggest wrist splinting at night as an adjuvant treatment modality. There is limited evidence that night splinting is more effective than no treatment in the short term; however, there is inadequate evidence of the efficacy and safety of one splint design over the others and combinations of other non-surgical interventions for CTS (12).

The rationale of carpal bone mobilization (CBM) instead of the unproven effects of the nerve gliding technique is that there is limited but promising evidence regarding its efficacy.

CBM for radicarpal joint is a physical therapy technique that includes moving the proximal row of carpal bones either dorsally to promote wrist extension or to the palmar side to promote wrist flexion. There is limited data; however, a small unblinded trial involving 21 people found that carpal bone mobilization significantly decreased pain intensity after 3 weeks compared with that of no treatment $(12,13)$. However, there was no significant benefit in hand function.
From the existing literature it is therefore considered that CBM may help CTS patients who are interested in nonsurgical treatments. However, lack of literature in this area requires structured research in CTS patients. Thus, in this randomized controlled trial, treating effects of carpal bone mobilization combined with night splinting is studied and compared with night splinting as the control group.

\section{Material and Methods}

\section{Patients}

In this randomized controlled 3-month follow-up study, 52 patients suffering from numbness, parestesia, and dysesthesia in the innervation area of the median nerve were assessed; 40 patients were electrodiagnosed to be concordant with the inclusion criteria, and they were randomly assigned into two groups. The inclusion criteria were as follows: CTS symptoms for at least 3 months with electrodiagnostic confirmation of mild to moderate nerve dysfunction, not undergoing physical and manual therapies, and no history of administration of steroid injections or drugs for neuropathic pain during this period. Exclusion criteria were as follows: previous or existing wrist fractures, recent surgical treatment relevant to CTS, presence of thenar atrophy, wrist deformity, diabetes mellitus, hypothyroidy, pregnancy, oncologic/ infectious disorders, or metal implants in the area of interest. Patients in both of the groups were advised not to use any kind of antiinflammatory drugs (nonsteriod antiinflammatory drugs or steroids) or medications for neuropathic pain (pregabalin, gabapentine etc) for the duration of the study.

Table 1. Comparison of the groups at baseline

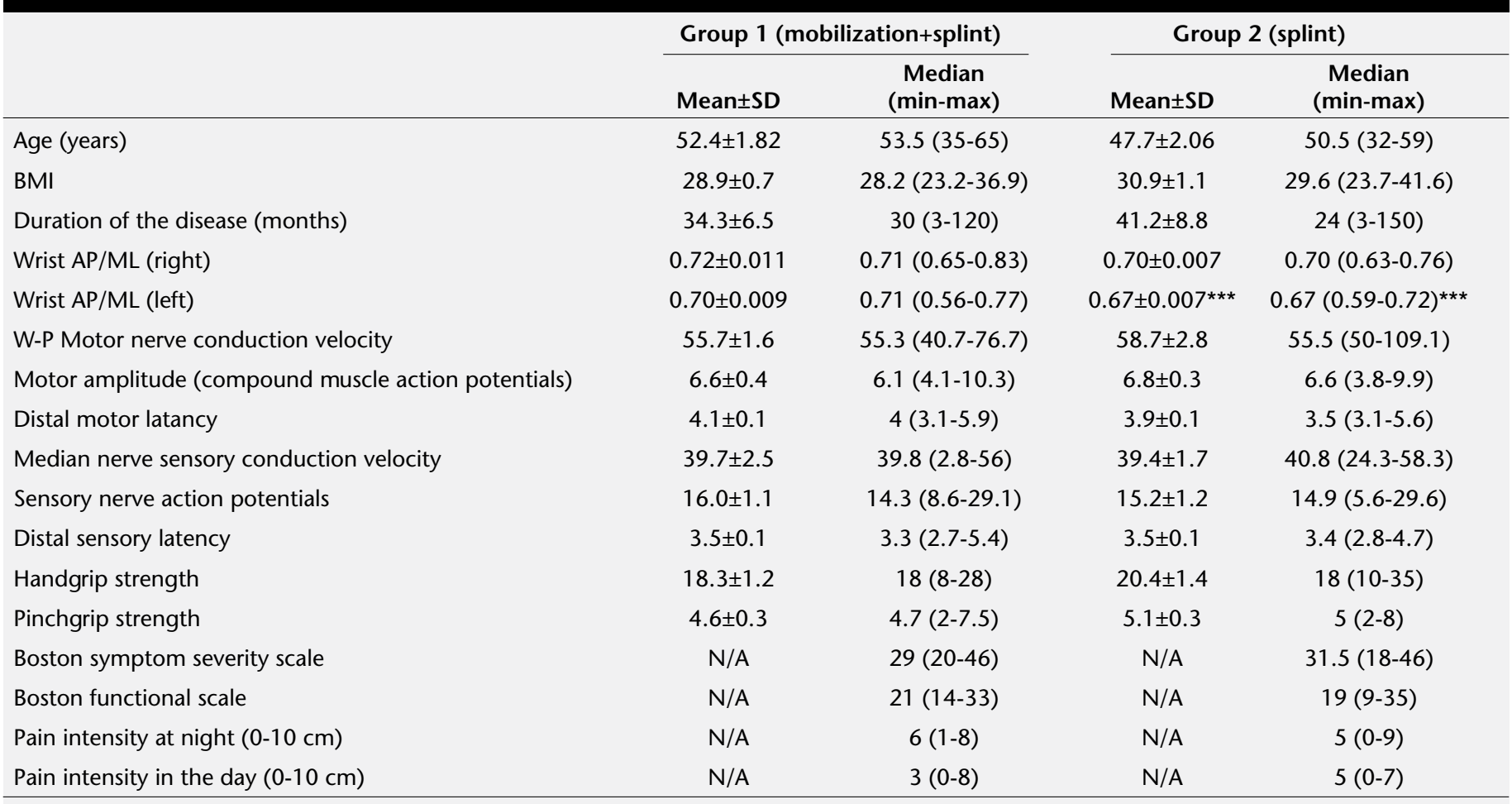

N/A: not applicable; SD: standard deviation; min: minimum; max: maximum; W-P: wrist-palm; ${ }^{* * *}=p<0.005$; AP: action potentials; ML: motor latencies; BMI: body mass index 


\begin{tabular}{|c|c|c|c|c|c|c|}
\hline & & \multicolumn{2}{|c|}{ Baseline evaluation } & \multicolumn{2}{|c|}{$3^{\text {rd }}$ month evaluation } & \multirow[b]{2}{*}{$\mathbf{p}$} \\
\hline & & Mean \pm SD & $\begin{array}{c}\text { Median } \\
(\text { min-max })\end{array}$ & Mean \pm SD & $\underset{(\text { min-max })}{\text { Median }}$ & \\
\hline \multirow[t]{2}{*}{ Handgrip strength } & G1 & $18.3 \pm 1.2$ & $18(8-28)$ & $21.4 \pm 1.7$ & $22(7-33)$ & 0.005 \\
\hline & G2 & $20.4 \pm 1.4$ & $18(10-35)$ & $21 \pm 1.6$ & $20(8-42)$ & 0.22 \\
\hline \multirow[t]{2}{*}{ Pinchgrip strength } & G1 & $4.6 \pm 0.3$ & $4.7(2-7.5)$ & $5.4 \pm 0.3$ & $5.2(3-8)$ & 0.021 \\
\hline & G2 & $5.1 \pm 0.3$ & $5(2-8)$ & $5.1 \pm 0.3$ & $5(2-9)$ & 0.77 \\
\hline \multirow[t]{2}{*}{ Boston symptom severity scale } & G1 & $\mathrm{N} / \mathrm{A}$ & $29(20-46)$ & $\mathrm{N} / \mathrm{A}$ & $17(12-44)$ & $<0.001$ \\
\hline & G2 & $\mathrm{N} / \mathrm{A}$ & $31.5(18-46)$ & $\mathrm{N} / \mathrm{A}$ & $23(11-43)$ & 0.001 \\
\hline \multirow[t]{2}{*}{ Boston functional scale } & G1 & $\mathrm{N} / \mathrm{A}$ & $21(14-33)$ & $\mathrm{N} / \mathrm{A}$ & $16.5(8-32)$ & 0.001 \\
\hline & G2 & $\mathrm{N} / \mathrm{A}$ & $19(9-35)$ & $\mathrm{N} / \mathrm{A}$ & $19(8-29)$ & 0.57 \\
\hline \multirow[t]{2}{*}{ Pain intensity at night $(0-10 \mathrm{~cm})$} & G1 & $\mathrm{N} / \mathrm{A}$ & $6(1-8)$ & $\mathrm{N} / \mathrm{A}$ & $0(0-8)$ & $<0.001$ \\
\hline & G2 & $\mathrm{N} / \mathrm{A}$ & $5(0-9)$ & $\mathrm{N} / \mathrm{A}$ & $0(0-8)$ & 0.001 \\
\hline \multirow[t]{2}{*}{ Pain intensity in the day $(0-10 \mathrm{~cm})$} & G1 & $\mathrm{N} / \mathrm{A}$ & $3(0-8)$ & $\mathrm{N} / \mathrm{A}$ & $0(0-8)$ & 0.003 \\
\hline & G2 & $\mathrm{N} / \mathrm{A}$ & $5(0-7)$ & $\mathrm{N} / \mathrm{A}$ & $1(0-7)$ & 0.011 \\
\hline \multirow[t]{2}{*}{ W-P Motor nerve conduction velocity } & G1 & $55.7 \pm 1.6$ & $\mathrm{~N} / \mathrm{A}$ & $54.3 \pm 0.9$ & $\mathrm{~N} / \mathrm{A}$ & 0.21 \\
\hline & G2 & $58.7 \pm 2.8$ & $\mathrm{~N} / \mathrm{A}$ & $56.1 \pm 1.3$ & $\mathrm{~N} / \mathrm{A}$ & 0.34 \\
\hline Motor amplitude (compound muscle & G1 & $6.6 \pm 0.4$ & $\mathrm{~N} / \mathrm{A}$ & $6.6 \pm 0.5$ & $\mathrm{~N} / \mathrm{A}$ & 0.05 \\
\hline action potentials) & G2 & $6.8 \pm 0.3$ & $\mathrm{~N} / \mathrm{A}$ & $7.2 \pm 0.3$ & $\mathrm{~N} / \mathrm{A}$ & 0.91 \\
\hline \multirow[t]{2}{*}{ Distal motor latancy } & G1 & $4.1 \pm 0.1$ & $\mathrm{~N} / \mathrm{A}$ & $4.2 \pm 0.3$ & $\mathrm{~N} / \mathrm{A}$ & 0.54 \\
\hline & G2 & $3.9 \pm 0.1$ & $\mathrm{~N} / \mathrm{A}$ & $4.1 \pm 0.1$ & $\mathrm{~N} / \mathrm{A}$ & 0.48 \\
\hline \multirow[t]{2}{*}{ Median nerve sensory conduction velocity } & G1 & $39.7 \pm 2.5$ & $\mathrm{~N} / \mathrm{A}$ & $41.9 \pm 1.8$ & $\mathrm{~N} / \mathrm{A}$ & 0.51 \\
\hline & G2 & $39.4 \pm 1.7$ & $\mathrm{~N} / \mathrm{A}$ & $39.1 \pm 1.8$ & $\mathrm{~N} / \mathrm{A}$ & 0.82 \\
\hline \multirow[t]{2}{*}{ Sensory nerve action potentials } & G1 & $16.0 \pm 1.1$ & $\mathrm{~N} / \mathrm{A}$ & $18.2 \pm 1.3$ & $\mathrm{~N} / \mathrm{A}$ & 0.03 \\
\hline & G2 & $15.2 \pm 1.2$ & $\mathrm{~N} / \mathrm{A}$ & $15.3 \pm 1.4$ & $\mathrm{~N} / \mathrm{A}$ & 0.70 \\
\hline \multirow[t]{2}{*}{ Distal sensory latency } & G1 & $3.5 \pm 0.1$ & $\mathrm{~N} / \mathrm{A}$ & $3.3 \pm 0.1$ & $\mathrm{~N} / \mathrm{A}$ & 0.012 \\
\hline & G2 & $3.5 \pm 0.1$ & $\mathrm{~N} / \mathrm{A}$ & $3.5 \pm 0.1$ & $\mathrm{~N} / \mathrm{A}$ & 0.27 \\
\hline
\end{tabular}

N/A: not applicable; G1: group 1; G2: group 2; SD: standard deviation; min: minimum; Max: maximum; W-P: wrist-palm

\section{Assignment}

Participants were randomly assigned to Group 1 (G1, mobilization+splint) and Group 2 (G2, splint) by an independent researcher. G2 was presumed to be a control group because of the common denominator, splint. Simple randomization was performed using a computer-generated table of random numbers. No stratification or blocking was performed during the randomization procedure.

\section{Intervention}

The subjects in G1 received CBM treatment $10 \mathrm{~min} /$ day and 3 times a week for 10 days and used neutral volar wrist splint at night. Patients in G 2 (Control Group) used neutral volar wrist splint at night for the duration of the study. (The splint fixed hands and fingers in functional position.) The treatment and assessment of the patients were conducted by two different physicians who were blind to treatment allocation.

Carpal bone mobilization practice includes dorsal-palmar glide at the radiocarpal joint and midcarpal (and radiocarpal) distraction. The forearm rests on a mat/table with the affected hand just extending off the table surface. The physician's hand grasps the patient's wrist just proximal to the styloid processes to stabilize the distal radioulnar joint. The mobilizing hand is placed over the proximal carpal row. The mobilization involves pushing and moving the row of carpal bones either dorsally to increase wrist extension or to the palmar side to increase wrist flexion.

For midcarpal distraction, the stabilizing hand is placed over the styloid processes and the mobilizing hand is placed over the distal carpal row. In addition, for radiocarpal distraction, the mobilizing hand is placed over the proximal carpal row. These mobilization techniques are used to improve wrist mobility and relieve ischemia and pain, thereby allowing a greater extension in the movement of the wrist because it is the closed-packed position of the wrist.

\section{Outcome Measures}

Body mass indexes (BMI), age, and duration of the disease were recorded for demographic evaluation. Wrist anteroposterior (AP) and medio-lateral $(\mathrm{ML})$ distance were measured by a caliper (compass) in milimeters (14). Handgrip strength 
was measured by a simple hand dynamometer. An average of three consecutive measurements was used for evaluation. Pinchgrip strength for the thumb was evaluated by a tip-totip pinchmeter with the same principle. Pain intensity in the day and night were evaluated by a numerical rating scale (0$10 \mathrm{~cm}$ ) (15). The Boston Carpal Tunnel Questionnaire (BCTQ) was used for symptomatic and functional evaluation $(16,17)$. Electroneuromyographic (ENMG) evaluation was performed at the Physical Therapy and Rehabilitation Department by the same physician for every patient at baseline and at the end of the study. The electrophysiologic evaluation included median distal sensory latencies (DSL), distal motor latencies (DML), sensory nerve action potentials (SNAP), compound muscle action potentials (CMAP), forearm median nerve conduction velocities (MNCV), and wrist-palm motor conduction velocities (MCV). All of the patients with CTS underwent electromyographic (EMG) examination of the abductor pollicis brevis (APB) muscle, and the spontaneous EMG activities were recorded. The evaluations were performed at baseline and at the $3^{\text {rd }}$ month follow-up.

This medical research was conducted according to the ethical principles of the Declaration of Helsinki. The university ethics committee approval and the patient's written informed consent were obtained.

\section{Statistical Analysis}

The statistical analysis was conducted by Statistical Package for the Social Sciences (SPSS Version 13.0 Chicago, IL, USA). Median and minimum-maximum values were given for BMl, age, duration of the disease, wrist AP/ML and ENMG measurements, pinchgrip and handgrip strengths, and Boston symptom severity/functional scales as descriptive statistics. Concordance of the data to normal distribution was tested using the Shapiro-Wilk test. Because the data were not normally distributed, the MannWhitney $\mathrm{U}$ test was used to determine whether any differences existed among the initial values of the groups for the variables (Table 1). According to the normality test, Wilcoxon's rank-sum test was used for intragroup comparisons by baseline characteristics (Table 2). Groups were compared with unpaired twosample t-test and Mann-Whitney $\mathrm{U}$ test with respect to percent changes and change scores. Pearson's or Fisher's chi-squared tests were used for comparing categorical variables (Table 3 ). The level of significance for all tests was $p<0.05$.

\section{Results}

Forty voluntary patients with CTS were enrolled in this study, with a median age of 53.5 years (35-65) and 50.5 years (32-59) in $\mathrm{G} 1$ and G2, respectively. BMls of the two groups were 28.2 (23.236.9 ) and 29.6 (23.7-41.6), respectively. Mean duration of the disease was $34.3 \pm 6.5$ months in $\mathrm{G} 1$ and $41.2 \pm 8.8$ months in G2. Patients in G1 had 25\% right hand, 20\% left hand, and 55\% bilateral CTS. Patients in G2 had 35\% right hand, 20\% had left hand, and $45 \%$ bilateral CTS. At baseline evaluation, groups were determined to be homogeneous for patient characteristics with the exception of the left wrist $\mathrm{AP} / \mathrm{ML}$ ratio, which was lower in the splint group, there by indicating an anatomical advantage $(p<0.005)$ (Table 1$)$.

\begin{tabular}{|c|c|c|c|c|}
\hline & \multicolumn{3}{|c|}{ Changes from baseline } & \multirow[b]{2}{*}{$\mathbf{p}$} \\
\hline & & Mean \pm SD & $\begin{array}{c}\text { Median } \\
(\text { min-max })\end{array}$ & \\
\hline \multirow[t]{2}{*}{ Handgrip strength } & G1 & $0.15 \pm 0.04$ & $0.13(-0.25 ; 0.56)$ & \multirow[t]{2}{*}{0.17} \\
\hline & G2 & $0.05 \pm 0.04$ & $0.05(-0.38 ; 0.5)$ & \\
\hline \multirow[t]{2}{*}{ Pinchgrip strength } & G1 & $0.25 \pm 0.1$ & $0.13(-0.33 ; 1.33)$ & \multirow[t]{2}{*}{0.04} \\
\hline & G2 & $0.06 \pm 0.08$ & $0(-0.43 ; 1.14)$ & \\
\hline \multirow{2}{*}{$\begin{array}{l}\text { Boston symptom } \\
\text { severity scale }\end{array}$} & G1 & N/A & $-12.5(-26 ; 5)$ & \multirow[t]{2}{*}{0.39} \\
\hline & G2 & N/A & $-8.0(-23 ; 5)$ & \\
\hline \multirow[t]{2}{*}{ Boston functional scale } & G1 & N/A & $-5.5(-18 ; 2)$ & \multirow[t]{2}{*}{0.01} \\
\hline & G2 & N/A & $0(-11 ; 5)$ & \\
\hline \multirow[t]{2}{*}{ Pain intensity at night $(0-10 \mathrm{~cm})$} & G1 & $\mathrm{N} / \mathrm{A}$ & $-5(-8 ; 2)$ & \multirow[t]{2}{*}{0.14} \\
\hline & G2 & N/A & $-4(-8 ; 2)$ & \\
\hline \multirow{2}{*}{$\begin{array}{l}\text { Pain intensity in the } \\
\text { day }(0-10 \mathrm{~cm})\end{array}$} & G1 & N/A & $-2(-7 ; 2)$ & \multirow[t]{2}{*}{0.53} \\
\hline & G2 & N/A & $-3(-7 ; 4)$ & \\
\hline \multirow{2}{*}{$\begin{array}{l}\text { W-P motor nerve } \\
\text { conduction velocity }\end{array}$} & G1 & $-0.01 \pm 0.02$ & $-0.02(-0.25 ; 0.31)$ & \multirow[t]{2}{*}{0.79} \\
\hline & G2 & $-0.02 \pm 0.03$ & $-0.04(-0.35 ; 0.26)$ & \\
\hline \multirow{2}{*}{$\begin{array}{l}\text { Motor amplitude } \\
\text { (compound muscle } \\
\text { action potentials) }\end{array}$} & G1 & $0.02 \pm 0.07$ & $0.04(-0.79 ; 0.56)$ & \multirow[t]{2}{*}{0.74} \\
\hline & G2 & $0.12 \pm 0.07$ & $0.07(-0.24 ; 1.16)$ & \\
\hline \multirow[t]{2}{*}{ Distal motor latancy } & G1 & $0.03 \pm 0.07$ & $-0.05(-0.22 ; 1.34)$ & \multirow[t]{2}{*}{0.23} \\
\hline & G2 & $0.04 \pm 0.04$ & $0(-0.21 ; 0.59)$ & \\
\hline \multirow{2}{*}{$\begin{array}{l}\text { Median nerve sensory } \\
\text { conduction velocity }\end{array}$} & G1 & $0.93 \pm 0.9$ & $0.01(-0.24 ; 17.7)$ & \multirow[t]{2}{*}{0.90} \\
\hline & G2 & $0.01 \pm 0.04$ & $0.03(-0.32 ; 0.5)$ & \\
\hline \multirow{2}{*}{$\begin{array}{l}\text { Sensory nerve action } \\
\text { potentials }\end{array}$} & G1 & $0.17 \pm 0.07$ & $0.15(-0.59 ; 0.72)$ & \multirow[t]{2}{*}{0.10} \\
\hline & G2 & $0.03 \pm 0.07$ & $0.06(-0.53 ; 1.03)$ & \\
\hline \multirow[t]{2}{*}{ Distal sensory latency } & G1 & $-0.05 \pm 0.02$ & $-0.06(-0.18 ; 0.16)$ & \multirow[t]{2}{*}{0.16} \\
\hline & G2 & $-0.009 \pm 0.02$ & $-0.02(-0.18 ; 0.27)$ & \\
\hline
\end{tabular}

N/A: not applicable; G1: group 1; G2: group 2; SD: standard deviation; min: minimum; Max: maximum; W-P: wrist-palm

One patient in the splint group discontinued intervention because of pregnancy, and the study was completed with the remaining 39 patients. 13 of the participants in G1 declared some sensation of warming or tingling during the procedure.

Patients in G1 showed significant improvement in all of the clinical variables $(p=0.005$ for hangrip strength, $p=0.021$ for pinchgrip strength, $p<0.001$ for Boston Symptom Severity Scale, $p<0.001$ for Boston Functional Scale, $p<0.001$ for pain intensity at night, and $p=0.003$ for pain intensity in the day). There was also an improvement in DSL and SNAP according to baseline evaluation ( $p=0.012 ; p=0.03$, respectively). In $G 2$, there was an improvement only in BCTQ symptom severity $(p=0.001)$ and night/day pain ( $p=0.001 ; p=0.011)$ intensity at the $3^{\text {rd }}$ month. Improvement in pinchgrip strength $(p=0.04)$ and $B C T Q$ functional status $(p=0.01)$ were superior in $\mathrm{G} 1$ when compared with that in $\mathrm{G} 2$ at the $3^{\text {rd }}$ month. 


\section{Discussion}

This study is designed to study the effects of CBM and wrist splinting in the management of CTS and to compare its effectiveness with wrist splinting. Significant improvement was achieved in function, strength, symptom severity, DSL, and SNAP of the intervention group (G1) at the $3^{\text {rd }}$ month, whereas there was only symptomatic improvement in G2. There was an anatomical advantage in $\mathrm{G} 2$ with a lower wrist $\mathrm{AP} / \mathrm{ML}$ ratio; however, this advantage did not lead to a better clinical response. It was observed that improvement in pinchgrip strength and functional status at the $3^{\text {rd }}$ month was superior in the intervention group when compared to control group. Nevertheless, ENMG measurements did not support this treatment effect.

Based on 16 studies, Page et al. (18) reported little benefit with low quality evidence for exercise and mobilization interventions for improving symptoms, functional ability, quality of life, and neurophysiologic parameters in CTS. The studies were heterogenous in terms of outcome, intervention, and timing. Of these, only four studies reported the primary outcome of interest, and three completed reported the outcome data sufficient for inclusion. According to another systematic review by Muller et al. (8), neutral wrist splinting improves overall and night time symptoms of patients with CTS (level of evidence, 4). Furthermore, night splinting alone markedly reduces symptom severity detected by nerve conduction testing and also increases functional ability of the hand compared to no treatment (level of evidence, 2b). Therefore, wrist splinting is considered to be an effective treatment modality in CTS. The present study highlighted the symptomatic effect of this treatment option in a follow-up period of 3 months. Because splinting is accepted to be associated with strong evidence of effectiveness, manual therapy with moderate/weak evidence of effectiveness is evaluated by using splinting as a control group.

In the same systematic review, two studies evaluated the efficacy and significant benefit of manual therapy on patients with CTS $(13,19)$. In Tal Akabi et al. (13), trial effects of two manual therapy techniques, CBM and median nerve mobilization, were investigated in patients with CTS. Both of the treatment groups consisted of seven patients, and a significant difference in symptomatic relief was observed when compared with the control group. However, these data should be interpreted with caution, considering the placebo or attention effect of the mobilization. CBM combined with flexor retinaculum stretch markedly increased the active range of motion and relieved dysesthesia compared with that of no treatment with evidence $2 \mathrm{~b}$ and 4 . However, no statistically significant difference was observed in the effectiveness of two interventions. Manente et al. (19) suggested a similar opinion and added that therapeutic effectiveness is related to specific manipulation techniques. This present study comprised 20 patients in each group, and it demonstrated the functional and strength ameliorating effects of CBM in addition to the literature.

In a case report (20) about chiropractic manipulative therapy, the patient favorably responded to the treatment of CBM combined with ultrasound, cryotherapy, muscle stimulation, massage, and wrist supports, and the pain diminished at the 3rd month. Va- lente (21) had reported a similar chiropractic attempt three times per week for 4 weeks to the patient's elbow and wrist using a low amplitude, low force, high velocity pressure. A significant increase in hand grip strength and normalization of motor and sensory latancies were noted. In a recent study comparable with ours (22), after therapy with six sessions of soft tissue and CBM demonstrated that a significant benefit was maintained in pain, Boston symptom severity, and functional scales, whereas there were no changes in electrophysiologic parameters. Burke et al. (23) investigated Granston instrument-assisted soft tissue mobilization twice a week for 4 weeks. There was a second group without instrument assistance. After both manual therapy interventions, improvements were maintained in nerve conduction latancies, wrist strength, and wrist motion in a period of 3 months. Although improvement was not different between the two manual therapy techniques, the data demonstrated the clinical efficacy of conservative treatment modalities for mild to moderate CTS. These trials can be considered as the anecdotal clinical evidence supporting CBM because improvement has been observed in response to a variety of manual therapy treatment approaches.

The limitations of the present study are the small sample sizes and having a "no treatment" group. However, the interesting results obtained may encourage manual therapists to make a more comprehensive research in this area. The mode of action for manual therapy is another point that requires clarification. Butler et al. (24) hypotheses may explain some improvement that is observed after treating the patients with mobilization. Alteration of the pressure or normalizing the pressure gradients in the nerve dispersion area may enhance the blood supply and ameliorate nerve conduction function. Therefore, carpal bone mobilization combined with neutral wrist splinting at night may be a treatment for the pathological neuropathy of the median nerve and its surrounding structures.

\section{Conclusion}

This research has demonstrated that functional status and pinchgrip strength of the patients wih CTS can be ameliorated by CBM treatment and can be recommended as an inexpensive, noninvasive, and effective treatment modality for the target population with CTS. Understanding anatomical, occupational, and environmental influences relevant in the course of the treatment and severity of the disease may help us to identify patients who would probably benefit from this type of conservative treatment. However, high quality randomized controlled trials still need to be conducted in this area for more convincing results.

Ethics Committee Approval: Ethics committee approval was received for this study from the ethics committee of Uludağ University, Faculty of Medicine.

Informed Consent: Written informed consent is obtained for every volunteer patient.

Author contributions: Concept - A.A., B.G.; Design - A.A., B.G.; Supervision - A.A.; Resource - A.A., B.G.; Materials - A.A., B.G.; Data Collection and/or Processing - B.G.; Analysis and/or Interpretation - A.A., B.G.; Literature Search - B.G.; Writing - A.A; Critical Reviews - A.A.; Other - B.G. 
Acknowledgements: We are grateful to Prof. Dr. Cihan Aksoy for his contribution to the application of this manipulation technique.

Conflict of Interest: No conflict of interest was declared by the authors.

Financial Disclosure: The authors declared that this study has received no financial support.

\section{References}

1. McCartan B, Ashby E, Taylor EJ, Haddad FS. Carpal tunnel syndrome. Br J Hosp Med 2005;73:199-202. [CrossRef]

2. Robinson LR. Electrodiagnosis of carpal tunnel syndrome. Phys Med Rehabil Clin N Am 2007;18:733-46. [CrossRef]

3. Jarvik J, Yuen E, Kliot M. Diagnosis of carpal tunnel syndrome: electrodiagnostic and MR imaging evaluation. Neuroimaging Clin N Am 2004;14:93-102. [CrossRef]

4. Kohara N. Clinical and electrophysiological findings in carpal tunnel syndrome. Brain Nerve 2007;59:1229-38.

5. McClure P. Evidence-based practice: an example related to the use of splinting in a patient with carpal tunnel syndrome. J Hand Ther 2003;16:256-63. [CrossRef]

6. Kaplan SJ, Glickel SZ, Eaton RG. Predictive factors in the nonsurgical treatment of carpal tunnel syndrome. J Hand Surg $\mathrm{Br}$ 1990;15:106-8. [CrossRef]

7. Stahl S, Yarnitsky D, Volpin G, Fried A. Conservative therapy in carpal tunnel syndrome. Harefuah 1996;130:241-95.

8. Muller M, Tsui D, Schnurr R, Biddulph-Deisroth L, Hard J, MacDermid JC. Effectiveness of hand therapy interventions in primary management of carpal tunnel syndrome: a systematic review. J Hand Ther 2004;17:210-28. [CrossRef]

9. Akalin E, El O, Peker O. Treatment of carpal tunnel syndrome with nerve and tendon gliding exercises. Am J Phys Med Rehabil 2002;81:108-13. [CrossRef]

10. Rozmaryn LM, Dovelle S, Rothman ER, Gorman K, Olvey KM, Bartko J]. Nerve and tendon gliding exercises and the conservative management of carpal tunnel syndrome. J Hand Ther 1998;11:171-9. [CrossRef]

11. Keith MW, Masear V, Chung KC, Amadio PC, Andary M, Barth RW, et al. American Academy of Orthopaedic Surgeons Clinical Practice Guideline on The Treatment of Carpal Tunnel Syndrome. The Journal of Bone and Joint Surgery 2010; 92:218-9. [CrossRef]
12. Page MJ, Massy-Westropp N, O'Connor D, Pitt V. Splinting for carpal tunnel syndrome. Cochrane Database Syst Rev 2012;7:CD010003. [CrossRef]

13. Tal-Akabi A, Rushton A. An investigation to compare the effectiveness of carpal bone mobilization and neurodynamic mobilization as methods of treatment for carpal tunnel syndrome. Man Ther 2000;5:214-22. [CrossRef]

14. Radecki P. A gender specific wrist ratio and the likelihood of a median nerve abnormality at the carpal tunnel. Am J Phys Med Rehabil 1994;73:157-62. [CrossRef]

15. Salaffi F, Stancati A, Silvestri CA, Ciapetti A, Grassi W. Minimal clinically important changes in chronic musculoskeletal pain intensity measured on a numerical rating scale. Eur J Pain 2004;8:283-91. [CrossRef]

16. Van Vliet MM, Maradey JA, Homa KA, Kerrigan CL. The usefulness of patient-reported measures for clinical practice. Plast Reconstr Surg 2013;132:105-12. [CrossRef]

17. Heybeli N, Kutluhan S, Demirci S, Kerman M, Mumcu EF. Assessment of outcome of carpal tunnel syndrome: a comparison of electrophysiological findings and a self-administered Boston questionnaire. J Hand Surg Br 2002;27:259-64. [CrossRef]

18. Page MJ, O'Connor D, Pitt V, Massy-Westropp N. Exercise and mobilisation interventions for carpal tunnel syndrome. Cochrane Database Syst Rev 2012;6:CD009899. [CrossRef]

19. Manente G, Torrieri F, Pineto F, Uncini A. A relief maneuver in carpal tunnel syndrome. Muscle Nerve 1999;22:1587-9. [CrossRef]

20. de Leon RP, Auyong S. Chiropractic manipulative therapy of carpal tunnel syndrome. J Chiropr Med 2002;1:75-8. [CrossRef]

21. Valente R, Gibson H. Chiropractic manipulation in carpal tunnel syndrome. J Manipulative Physiol Ther 1994;17:246-9.

22. Maddali Bongi S, Signorini M, Bassetti M, Del Rosso A, Orlandi M, De Scisciolo $G$. A manual therapy intervention improves symptoms in patients with carpal tunnel syndrome: a pilot study. Rheumatol Int 2013;33:1233-41. [CrossRef]

23. Burke J, Buchberger DJ, Carey-Loghmani MT, Dougherty PE, Greco DS, Dishman JD. A pilot study comparing two manual therapy interventions for carpal tunnel syndrome. J Manipulative Physiol Ther 2007;30:50-61. [CrossRef]

24. Butler D. Mobilization of the Nervous System, 1st edn, Churchill Livingstone, Melbourne 1991; p45. 